\title{
Гибридная война и изменяющийся характер конфликта
}

\section{Бастиан Гиегерих}

Международный институт стратегических исследований (МИСИ), Лондон, http://www.iiss.org

Резюме: Идея, что международный конфликт может во все большей степени включать гибридную войну и гибридные угрозы, оживила споры между истеблишментами в сфере безопасности и обороны накануне Варшавского саммита НАТО в 2016 году. Хотя Альянс позиционировал проблему гибридной войны в конкретном контексте кризиса между Россией и Украиной и в 2014 году начал работу по подготовке НАТО к эффективному ответу на гибридные угрозы, масштаб этого вызова оказался гораздо большим, и его основная динамика часто лежит вне военной сферы. В этой статье сделан обзор последних концептуальных дебатов о гибридной войне, который приводит к выводу, что гибридные конфликты не поддаются нашим попыткам втиснуть их в известные категории и позиционировать их определенно в спектре конфликтов между войной и миром. Для противодействия гибридным угрозам государства-члены НАТО будут должны инвестировать ресурсы в укрепление устойчивости и конвенционального сдерживания.

Ключевые слова: гибридные угрозы; конфликт; устойчивость; сдерживание; стратегия.

В период от «маленьких зеленых человечков» в Крыму до «маленьких голубых человечков» в Южно-Китайском море идея, что международный конфликт во все большей степени можно рассматривать как гибридную войну и гибридные угрозы, оживила дебаты в среде истеблишментов НАТО в сфере 
безопасности и обороны и за их пределами. ${ }^{1}$ Действительно, термин «гибридная война» стал чем-то вроде скрепки для словаря европейской политики в сфере безопасности. НАТО и ЕС работают над созданием стратегических документов, направленных на укрепление оборонных способностей и предотвращение гибридных атак. Разрабатывая документы, касающиеся обзора состояния безопасности и обороны, национальные правительства часто ссылаются на необходимость рассматривать гибридные угрозы. Журналисты приняли термин «гибридная война» как сокращенное обозначение русской тактики на Украине, очевидно полагая, что читатели уже знают, что он означает.

В декларации саммита НАТО в Уэльсе от 5 сентября 2014 года сказано, что лидеры «обеспечат способность НАТО эффективно реагировать на конкретные вызовы, создаваемые угрозами гибридной войны, в которой очень координированным образом применяется большой набор открытых и скрытных военных, пара-военных и гражданских средств. Важно, чтобы Альянс располагал необходимыми инструментами и процедурами для сдерживания и эффективной реакции на угрозы гибридной войны и способностями укреплять национальные силы». ${ }^{2}$

Тогда как уэльская декларация ставит проблему гибридной войны в конкретном контексте российско-украинского кризиса и инициированных усилий по подготовке НАТО к эффективной реакции на такие угрозы, охват угрозы гораздо шире, и ее основная динамика очень часто лежит вне военной сферы. Это подтверждается более ранней работой, проводимой Союзным командованием НАТО по трансформации под наименованием «Противодействие гибридным угрозам», но похоже, выводы, к которым пришли в то время, не были должным образом учтены, пока незаконная аннексия Крыма Россией не стала суровым напоминанием. ${ }^{3}$

\section{Почему мы должны быть озабочены?}

Рассматривая конфликт в Украине, аналитики приходят к различным оценкам. Антон Денг и Майкл Шуриян утверждают, что украинский конфликт показывает, что использование гибридных средств для проецирования мощи может быть важной тенденцией, которая будет формировать характер бу-

1 Оба термина относятся к личному составу без знаков различия, смотри: Vitaly Shevchenko, "'Little Green Men' or 'Russian invaders'?” BBC News, 11 March 2014; Christopher Cavas, "China's 'Little Blue Men' Take Navy's Place in Disputes," Defense News, 2 November 2015.

2 NATO, "Wales Summit Declaration Issued by the Heads of State and Government participating in the meeting of the North Atlantic Council in Wales," 5 September 2014, http://www.nato.int/cps/en/natohq/official_texts_112964.htm (по состоянию на 11 декабря 2015).

3 Резюме работы СКТ смотри в Michael Miklaucic, "NATO Countering the Hybrid Threat," 23 September 2011, http://www.act.nato.int/nato-countering-the-hybridthreat (по состоянию на 11 декабря 2015). 
дущих угроз. ${ }^{4}$ Британская Стратегия национальной безопасности и сопутствующий ей Стратегический обзор обороны и безопасности, опубликованные в конце ноября 2015 года, констатируют, что «незаконная аннексия Крыма в 2014 году и продолжающаяся поддержка сепаратистов в Восточной Украине путем использования позволяющей отрицать свою причастность гибридной тактики и манипулирования СМИ показало намерение России разрушить более охватные международные стандарты сотрудничества с целью обеспечить реализацию своих предполагаемых интересов». ${ }^{5}$ В этих стратегических документах гибридные угрозы рассматриваются как проблемы первого уровня, которые могут оказать влияние напрямую на Объединенное королевство, и как проблемы второго уровня, которые могли бы начаться как гибридное нападение на союзника. Диего Руиз Палмер обобщает цель России как достижение «решающих в политическом смысле результатов, если возможно, без использования или со скрытным использованием военной силы, оставаясь в готовности действовать военным образом с опустошительным результатом на оперативном уровне ..., направленным на достижение решающего политического преимущества на грани войны ». ${ }^{6}$ Основным преимуществом такого подхода является то, что большая часть деятельности, связанной с гибридным конфликтом, происходит ниже порога, который большинство западных наблюдателей считает вооруженным конфликтом, не говоря уже о войне.

Самуель Чарап из Международного института стратегических исследований полагает, что этот российский подход не уйдет далеко вне специфических условий конфликта на Украине. Чарап считает, что у России нет «доктрины гибридной войны, которую можно было бы эффективно применять против НАТО», и предупреждает, что переэкспонирование проблемы гибридной войны само по себе является опасностью: «Российские стратеги считают, что США имеют намерение рискнуть и вести ограниченную, гибридную операцию в России ... совершенно так же, как стратеги НАТО считают, что Россия готова рискнуть тем же самим на территории [НАТО]». ${ }^{7}$ Кен Касапоглу, в весьма нюансированном анализе, указывает на то, что НАТО сталкивается не с новой российской военной стратегией, но Альянс должен понять, что в России вокруг концепции нелинейной войны появилось «новое военное мышление, которое привело к сдвигам на стратегическом, оперативном и тактическом уровне наряду с новым доктринальным боевым

4 Anton Dengg and Michael Schurian, Zum Begriff der Hybriden Bedrohungen, in Vernetzte Unsicherheit - Hybride Bedrohungen im 21. Jahrhundert, ed. A. Dengg and M. Schurian (Vienna: Landesverteidigungsakademie, 2015), 23-75.

5 HM Government, National Security Strategy and Strategic Defence and Security Review 2015. A Secure and Prosperous United Kingdom, November 2015, Cm 9161, c. 18 .

6 Diego A. Ruiz Palmer, "Back to the Future? Russia's Hybrid Warfare, Revolutions in Military Affairs, and Cold War Comparisons," Research Paper No. 120 (NATO Defense College, October 2015), 2.

7 Samuel Charap, "The Ghost of Hybrid War," Survival 57:6 (2015): 53, 57. 
порядком и новой военной стратегической культурой». ${ }^{8}$ Лоренс Фрийдман предлагает еще одну точку зрения, утверждая, что Россия, возможно, и хорошо вела гибридную войну на Украине, но на деле не добилась больших успехов, а преимущества для нападающего, предоставляемые гибридными средствами, сильно преувеличены. ${ }^{9}$

Кроме вопроса, является ли поведение России на Украине моделью гибридной войны, и если да, то насколько широко эту модель можно обобщать и насколько она была успешной, начался основательный спор вокруг вопроса об уместности самого ярлыка. Для некоторых обозревателей нынешняя преувеличенная озабоченность гибридной войной является причудой в лучшем случае, и свидетельством интеллектуальной лени в худшем. Сторонники такой точки зрения утверждают, что они не видят ничего нового, в всего лишь современную интерпретацию проверенного временем сочетания конвенциональных и неконвенциональных подходов. Сторонники другой точки зрения могли бы утверждать, что гибридная война стала удобным ярлыком для обозначения всех проблем, связанных с изменяющимся характером конфликта, которых мы на данный момент не понимаем. В целом, однако, хотя о характере и степени важности гибридной войны можно спорить, игнорирование развития гибридного подхода к конфликту является серьезной опасностью для Альянса.

Хорошим аналитическим исходным пунктом для выяснения этой концепции является работа Фрэнка Хоффмана, не на последнем месте и из-за того, что Хоффман один из исследователей, которые ввели этот термин в его современной реинкарнации. Он подчеркивает, что гибридная угроза является не только простым сочетанием разнообразных акторов, тактик и подходов. Гибридные проблемы инициируют разные режимы конфликта, и именно этот новый синтез представляет собой проблему, с которой трудно справиться, поскольку он спутывает двоичную концепцию Запада о войне и мире, о военных и невоенных средствах, о конвенциональных и нерегулярных подходах. ${ }^{10}$ В недавнем комментарии по вопросу Хоффман сказал, что западные акторы "думают о вещах в понятиях черно-белой палитры», и им нужно существенно улучшить понимание конфликта в пространстве между двумя крайностями в серой зоне. ${ }^{11}$ С учетом того, что смешение схем кон-

8 Can Kasapoglu, “Russia's Renewed Military Thinking: Non-Linear Warfare and Reflexive Control," Research Paper No. 121 (NATO Defense College, November 2015), 11.

9 Lawrence Freedman, "Ukraine and the Art of Limited War," Survival 56:6 (2014): 7-38.

10 Frank G. Hoffman, Conflict in the $21^{\text {st }}$ Century: The Rise of Hybrid Wars (Arlington, VA: Potomac Institute for Policy Studies, 2007), на www.potomacinstitute.org/images/ stories/publications/potomac_hybridwar_0108.pdf (по состоянию на 11 декабря 2015); James N. Mattis and Frank G. Hoffman, "Future Warfare: The Rise of Hybrid Wars," Proceedings Magazine, 132:11 (2005), http://milnewstbay.pbworks.com/f/ MattisFourBlockWarUSNINov2005.pdf (по состоянию на 11 декабря 2015).

11 Цитировано в Thomas Gibbons-Neff, "The 'new' type of war that finally has the Pentagon's attention," Washington Post, 3 July 2015, www.washingtonpost.com/world/ national-security/the-new-type-of-war-that-finally-has-the-pentagons-attention/ 
фликта, которые раньше рассматривались как не связанные между собой, является ядром гибридных угроз, логически следует, что гибридные угрозы и гибридная война будут появляться во множественных обличиях - этот вызов продолжит развиваться.

Не обязательно признавать новую гибридную парадигму целиком, чтобы признать, что гибридная война и гибридные угрозы в настоящее время на самом деле оказывают прямое влияние на европейскую безопасность и могут служить полезным конструктом при обдумывании способностей, необходимых для предотвращения и для противодействия определенным вызовам современности. Само по себе сочетание регулярных и нерегулярных сил на одном театре операций, конечно, является весьма конвенциональной стратегией. ${ }^{12}$ Новой, однако, является непосредственная актуальность этой стратегии для сегодняшней безопасности Европы. Гибридные игроки на Востоке и на Юге напрямую угрожают европейским интересам в сфере безопасности, и даже, похоже, бросают вызов всему евро-атлантическому порядку безопасности. Амбиции Владимира Путина сделать Россию великой силой несовместимы со структурой принципов и ценностей европейских институтов безопасности. Что касается российского государства, утвердившиеся методы международных отношений, в том числе их военные измерения, должны все еще быть эффективными. С другой стороны, халифат Абу Бакр аль-Багдади, варварство и нигилистическое презрение к человечности так называемого Исламского государства (ИГ) делают маловероятным, если не просто абсурдным, договорное решение с этим актором. И тот, и другой бросают гибридные вызовы.

Таким образом, гибридные войны настигли Европу с двух направлений, и в весьма разных формах. На Востоке это государственный игрок, Россия под управлением Путина, который преднамеренно использует негосударственные средства, и на Юге это негосударственный актор, Исламское государство (ИГ), чьи лидеры пытаются создать структуры, которые как минимум подобны государственным, и у которых тоже есть доступ к насильственным средствам, которые обычно разрешены государствам, или точнее их вооруженным силам. Эти враги Европы являются гибридными субъектами в смысле, что они могут использовать все наличные инструменты мощи на театре операций координированным способом, и при некоторой степени централизованного управления. В то же время, они преследуют те же самые цели, которые всегда мотивировали акторов в вооруженных конфликтах: достижение психологического и физического преимущества. В этой борьбе гибридная война не отличается от других форм войны.

2015/07/03/b5e3fcda-20be-11e5-84d5-eb37ee8eaa61_story.html (по состоянию на 11 декабря 2015).

12 Max Boot, "Countering Hybrid Warfare," in Armed Conflict Survey 2015 (Abingdon: International Institute for Strategic Studies, 2015), 11-20. 


\section{Последствия гибридного подхода к конфликту и рекомендации}

\section{относительно политики в этом направлении}

Как было высказано предположение, последствия гибридного подхода к конфликту имеют широкий спектр и затрагивают концепции, аспекты материальных способностей, правовые вопросы и институциональные инновации. ${ }^{13}$ Гибридный конфликт не поддается попыткам втиснуть его в знакомые категории. Он не просто находится между конфликтами, в которых движущей силой является государство, и конфликтами, в которых движущей силой является негосударственный субъект, как предполагается в последнем варианте военной стратегии США. ${ }^{14}$ У этого конкретного стратегического документа, однако, есть то преимущество, что конфликт рассматривается в качестве континуума, а не предпосылаются такие четкие условия, как война и мир. Гибридный конфликт занимает место где-то в промежуточном пространстве, или так сказать, на стыках традиционных способов мышления.

Что касается ответной реакции, ключевым концептуальным новшеством было открытие, или возможно переоткрытие, упругости как основного принципа политики безопасности. Упругость в контексте национальной безопасности касается способности обществ справляться с угрозами и рисками, адаптироваться к ним и восстанавливаться в случае нападения или другого события, не теряя способность обеспечивать выполнение основных функций и предоставление основных услуг членам этого общества. ${ }^{15}$ Вкратце, это способность прогибаться изящно при оказании давления и затем выпрямляться обратно. Упругость на первом месте является вопросом уменьшения собственных уязвимостей. Учитывая, что это уменьшает вероятность того, что гибридные атаки будут достигать своих целей, упругость также способствует сдерживанию гибридного контекста, уменьшая потенциальные выигрыши, которые любой нападающий может надеяться осуществить.

Если гибридная война является обратной плохой стороной комплексного подхода НАТО, понятно, что НАТО должно удвоить свои усилия, направленные на то, чтобы сделать комплексный подход более успешным и, в частности, упрочить связи с другими организациями. Очевидно, что даже распределение ответственностей на национальном уровне и распределение задач между НАTO, ЕС и другими организациями не будет простым делом. Превенция и защита против гибридных угроз должны включать участие всех государственных органов на национальном и местном уровне, частный сектор и, возможно, общества в целом. Синергии сетевого подхода, так хорошо

13 Patryk Pawlak, "Understanding Hybrid Threats," European Parliamentary Research Service (EPRS), 24 June 2015.

14 US Joint Chiefs of Staff, The National Military Strategy of the United States of America 2015 (Washington, DC: DOD, 2015), 4.

15 Oliver Tamminga, "Zum Umgang mit hybriden Bedrohungen. Auf dem Weg zu einer nationalen Resilienzstrategie," SWP-Aktuell 92 (2015): 3. 
смотревшейся в теории, очень трудно добиться на практике. Не существует одной единственной ответственности на защиту от гибридных угроз, и поэтому нет очевидного центра принятия решений. Спектр таких угроз широк, и систематическое исследование вопроса, какая организация и какой орган отвечает за каждый элемент ответной реакции на гибридное нападение, даст картину, которая покажет очевидным образом, что на национальном и на международном уровне наличные инструменты недостаточно взаимосвязаны. Как утверждает Кристиан Мьолинг, гибридная политика безопасности является адекватным ответом на гибридные угрозы с целью встретить «противника на невоенной арене с тем, чтобы предотвратить эскалацию конфликта до использования военной силы». ${ }^{16}$

Из гипотетического риска, что «Россия поддастся искушению оказать давление или предпринять ограниченную агрессию против одного из Союзников, рассчитывая, что это не приведет к ответным действиям НАТО», проистекает множество последствий, связанных со способностями и ресурсами НАТО. ${ }^{17}$ Нет необходимости искренне верить, что это есть действительно вероятный курс действий России: даже восприятие, которое определенно имеет место для некоторых из союзников, что это может быть мыслимой стратегией России, является очень сильным дестабилизирующим фактором. Поэтому НАТО придется пойти намного дальше по пути военной адаптации и военных гарантий. Если в 2015 году было отмечено, что учения «Трайдент джанкчер» были самыми масштабными за последние десять лет, в следующие годы может появиться необходимость в проведении учений на гораздо более высоком уровне, что касается численности участвующих войск. Штабы НАТО были укомплектованы офицерами, которые умели планировать и осуществлять многонациональные передвижения войск на корпусном уровне и выше. Сегодня эти умения и этот опыт частично потеряны и их надо восстановить, так же как необходимо улучшить структуры для принятия решений и бюрократические процедуры с учетом того факта, что в кризисных ситуациях, которые не являются официальным состоянием войны, будут иметь место значительные международные передислокации личного состава и материальных ресурсов.

Есть необходимость предпринять действия в сфере конвенционального военного сдерживания. Это включает постоянное расположение значительных сил НАТО на территории подверженных риску государств-членов, предпочтительнее в форме многонациональных формирований. Стратегия сдерживания не должна основываться единственно на предположении, что в случае кризиса, НАТО будет в состоянии быстро и легко укрепить свои силы. Государства-члены НАТО так же уже начали создавать специализированные военные формирования для обеспечения обороны против гибридных атак и для реакции на гибридные конфликты в других местах. Ярким примером

${ }^{16}$ Christian Mölling, "From Hybrid Threats to Hybrid Security Policy," Ethics and Armed Forces 2 (2015): 2.

17 Ruiz Palmer, "Back to the Future," 10. 
является британская $77^{-я}$ бригада, комбинированное формирование регулярной армии и армейского резерва. Недавно сформированная $77^{-я}$ бригада сфокусирована на разведке, наблюдении и рекогносцировке. Она приспособлена к ведению современных информационных операций, в частности для противодействия гибридной войне.

Чтобы усилить пресловутую упругость, систематическая идентификация уязвимостей к гибридным угрозам должна стать основным приоритетом. В число таких уязвимых элементов могут входить маргинализированные группы в обществе, которые могут стать объектом действий, направленных на их радикализацию или идеологическую мобилизацию. Возможно, это будут случаи энергетической зависимости, которые могут при соответствующем политическом давлении превратиться в средства гибридной войны. Серьезные инвестиции необходимы в сферу разведывательного анализа, прогнозирования состояния безопасности и слабых сигналов. Другой важной сферой деятельности, направленной против гибридных угроз, является раннее предупреждение и оценивание ситуации, которые соответствуют характеру этой формы конфликта. В этом направлении необходимо обмениваться результатами работы национальных разведывательных служб и их оценкой в рамках международной сети ЕС и НАТО более быстрыми темпами, чем это происходит сейчас. Даже слабые сигналы, указывающие на гибридное нападение, могут выявить схему, если имеет место координация такого типа.

Наращивание способностей в этой области позволит НАТО лучше понять феномен гибридной угрозы, разработать критерии оценки событий, систематически заниматься уязвимостями и прогнозировать, как гибридные угрозы будут развиваться в будущем. В настоящее время у НАТО отсутствуют механизмы финансирования, которые позволили бы воспользоваться преимуществами информации из открытых источников, которую могут предоставить мозговые центры и эксперты аналитики. Бюджет НАТО на публичную дипломатию расходуется на события, которые могут иметь или не иметь аналитическую ценность. СКТ НАТО имеет академическую просветную программу, но ее мероприятия дают более хорошие результаты при формировании и поддерживании сетей, чем при использовании активных партнерств для интегрирования внешних анализов в процессы НАТО, если и когда это было бы необходимо.

Информационные операции являются интегральной частью гибридной войны, используемой для формирования нарративов и, в целом, для оказания влияния на формирование политических мнений среди целевых групп населения. Стратегическая коммуникация предлагает возможность противодействовать этому, но только если она когерентна, последовательна, своевременна и точна. Хотя это не простое дело, странно наблюдать насколько трудно НАТО и ЕС осуществляют даже основную координацию. К примеру, 22 июня 2015 года ЕС принял План действий по стратегической коммуникации. До этого, в июле 2014 года, НАТО учредило Центр квалифи- 
кации по стратегическим коммуникациям в Латвии с той же целью. В плане действий ЕС нет упоминания об этом центре, а рабочий план за 2015 год, опубликованный на вебсайте центра НАТО, не ставит в число приоритетов сотрудничество с ЕС. ${ }^{18}$ Между тем, обе организации заявляют, что как раз в этой сфере необходима тесная координация. В случае вызовов, которые выходят за рамки традиционных категорий анализа, субъекты, принимающие решения, и эксперты должны быть в равной степени креативными. Тут суть не в том, что такие события, как вторжение в Крым, становятся моделью будущего конфликта, но в том, что принципы, на которых они основывались, станут источником информации для следующих претендентов, а гибридность в качестве базового фактора в конфликте останется надолго.

\section{6 авторе}

Доктор Бастиан Гиегерих является директором отдела по оборонным и военным анализам Международного института стратегических исследований (МИСИ) в Лондоне. Он один из авторов Обзора военного баланса и Стратегического обзора МИСИ. С 2010 по 2015 год Бастиан Гиегерих работал в Министерстве обороны Германии в качестве исследователя и сотрудника, участвующего в определении политики, а также был консультирующим старшим научным сотрудником МИСИ по европейской безопасности. У него степень магистра в сфере политических наук, полученная в Университете Потсдама, и степень доктора по международным отношениям, полученная в Лондонской школе экономики. Бастиан является автором и редактором нескольких книг по вопросам европейской безопасности и обороны. Его статьи появляются в таких журналах, как Survival, Security Studies u International Politics, а также и в разных печатных СМИ. Бастиан вел курсы по международным отношениям, военным исследованиям и публичной администрации в Лондонской школе экономики, в Университете Потсдама и в Университете Касселя. E-mail: Giegerich@iiss.org.

18 European Union, “Action Plan on Strategic Communication," Ref. Ares(2015)2608242, 22 June 2015, http://eap-csf.eu/assets/files/Action\%20PLan.pdf (по состоянию на 31 октября 2015); NATO Strategic Communications Centre of Excellence, http://www.stratcomcoe.org/ about-us (по состоянию на 31 октября 2015). 